\title{
A Thermal Conduction Analysis of Proposed Lateral and Downstream Row 1 Module Plate Designs
}

\author{
M. A. Shadday and L. L. Hamm \\ Westinghouse Savannah River Company \\ Aiken, SC 29808
}

This document was prepared in conjunction with work accomplished under Contract No. DE-AC09-96SR18500 with the U.S. Department of Energy.

DISCLAIMER

\begin{abstract}
This report was prepared as an account of work sponsored by an agency of the United States Government. Neither the United States Government nor any agency thereof, nor any of their employees, makes any warranty, express or implied, or assumes any legal liability or responsibility for the accuracy, completeness, or usefulness of any information, apparatus, product or process disclosed, or represents that its use would not infringe privately owned rights. Reference herein to any specific commercial product, process or service by trade name, trademark, manufacturer, or otherwise does not necessarily constitute or imply its endorsement, recommendation, or favoring by the United States Government or any agency thereof. The views and opinions of authors expressed herein do not necessarily state or reflect those of the United States Government or any agency thereof.
\end{abstract}

This report has been reproduced directly from the best available copy.

Available to DOE and DOE Contractors from the Office of Scientific and Technical Information, P. O. Box 62, Oak Ridge, TN 37831; prices available from (423) 5768401.

Available to the public from the National Technical Information Service, U.S. Department of Commerce, 5285 Port Royal Road, Springfield, VA 22161.

\section{Summary}

In the event of a LOCA in the Accelerator Production of Tritium (APT) blanket heat removal system that results in dryout of one or more modules, the decay heat must be dissipated by the cavity flood system. Thermal conduction modeling of the highest power plate in a lateral or downstream row 1 module shows that the cavity flood system can adequately dissipate the heat of an internally dry row 1 module with plates up to 7.5 inches long. The current blanket design has 4.0 inch plates in the high power inner modules close to the target and longer plates in the lower power modules further removed from the target. This study shows that the short plates in the inner modules can be safely replaced, with respect to the thermal criteria for safety analyses, by the longer plate design, resulting in a single plate design for all lateral modules. Uniform size plates simplify fabrication and assembly demands/costs.

\section{Introduction}

The cavity flood system is designed to be the primary safeguard for the integrity of the blanket modules during loss of coolant accidents (LOCAs). In the unlikely event that the internal flow passages in a module dryout, decay heat in the metal structures will be dissipated to the cavity flood system through the module walls. There is a design proposal under consideration to utilize a single 7.5 inch plate design in the APT blanket lateral modules. Currently, the lateral and downstream row 1 modules are designed with 4.0 inch plates, and longer plates are utilized in the lower power outer row modules. There are many benefits (e.g., fabrication costs, assemblage error reductions) to having a single plate design. The purpose of this study is 
to determine if the longer plate design meets the safety criterion that, when a module is internally dry, it can be adequately cooled by the cavity flood system.

\section{Problem Description}

A LOCA in the blanket heat removal systems (HRS) could result in one or several of the modules becoming hydraulically isolated and ultimately drying out. The decay heat in those modules would then need to be dissipated by the cavity flood system. The highest powers occur in the row 1 modules, so a demonstration of adequate cooling of these modules is bounding. The temperature limit for the modules is $150^{\circ} \mathrm{C}$. This limit is based on a 10,000 hour exposure time interval. There is a decoupler on the target side of each row 1 module with a very narrow gap between this decoupler and row 1 module (conservatively assumed not to exist in these analyses), and a one inch gap separates the row 1 and row 2 modules. When the cavity flood system is activated, the one inch gap is flooded, and this side of the module is cooled. To determine the adequacy of cavity flood cooling, post-beam shutdown transient heat transfer in the highest power row 1 module plate was modeled with a three-dimensional thermal conduction code (HEATEL). Only the one inch gap end of the plate was cooled. The peak temperature in the plate, both spatially and temporally, was determined. The cavity flood system was assumed to be operative and capable of handling the heat loads.

\section{Description of the Thermal Conduction Model}

The highest power plate (referred to as the "hot" plate) in the lateral or downstream row 1 modules was modeled with HEATEL, a transient three-dimensional thermal conduction code. Considering a single plate substantially reduces the size and complexity of the numerical model, and the thermal behavior of the hot plate is bounding, because thermal conduction to adjacent plates with lower power generation is not accounted for. Three plate designs were modeled: (1) a nominal 4.0" plate, which represents the present design; (2) a nominal 7.5" plate, which represents the proposed design; and (3) a plate with intermediate dimensions. The nominal 4.0" plate represents the current row 1 design which is a thicker plate than the original design. The intermediate size plate was analyzed to check for possible nonlinear effects in peak temperature versus plate size. This provides increased confidence to designers for future size optimization studies. Figure 1 shows horizontal cross-sections of the three plate designs, as well as a horizontal crosssection of the original plate design that was the basis for safety analysis in the initial draft of the Preliminary Safety Analysis Report (PSAR) [1]. The cross-sections also show the HEATEL finite element grids for the plates. To expedite development of finite element grids for each of the three plate designs being modeled, the existing original grid was stretched to the lengths and widths of the three new plate designs. The stretching process resulted in some shape distortion. Due to the low heat loads associated with shutdown conditions it is expected that precise geometrical grids are not required. The exact plate dimensions for the three designs are shown in Figure 1. Figure 2 shows the three-dimensional mesh of plate $\mathrm{C}$ with 20 vertical cells. The schematic is compressed by a scale of 10:1 in the vertical direction. The original plate design has an aluminum cladding thickness of 55 mils, and the presence of a uniform one mil air-filled gap between the lead and the aluminum is assumed. These dimensions were distorted in the stretching process. By design the plates are narrower at the high power decoupler ends. They are stacked together in the "y" direction of Figure 1 to form a module. With the cross-sections of adjacent plates being mirror images, the scalloped sides of the plates form the module internal flow channels. A consistent scale factor is used for each mesh in Figure 1 to show the relative plate sizes. As shown in Figure 1, a significant increase in plate volume occurs when going from the original design to the proposed $\mathrm{C}$ design.

Vertical and horizontal lengthwise power distributions in a plate are included in the model. The power distribution in the horizontal direction normal to the stacked plates is accounted for by modeling the highest power or hot plate in the module. Three row 1 modules were considered, and the hot plate of the 
downstream row 1 module was determined to have the highest power. Spatial power density distribution data [3], for a blanket with nominal 4" row 1 module plates was utilized, and the power density distributions along the lengths of the nominal 5.5" and 7.5" plates were extrapolated from this data. The extrapolated horizontal power density distributions were integrated and normalized with the integrated power density distribution for the nominal 4" plate to determine extrapolated plate powers for the two longer plate designs. Table 1 shows the pre-incident plate powers for the hot plate in the three modules considered. To simplify input in the model, all of the power is deposited in the lead. Figure 3 shows the axial power density profile, and Fig. 4 shows the horizontal lengthwise power density profile for the hot plate of the downstream row 1 module. The points in Figure 4 with lateral distances of four inches or greater are extrapolated values. For the short and intermediate length plate designs, appropriate portions of the horizontal power density profile, shown in Figure 4 were used. Figure 5 shows the power density distribution that is in the horizontal plane and perpendicular to the beam, for the downstream row 1 module. The hot plate is the one that is approximately $-29.3 \mathrm{~cm}$ from the beam center.

The decoupler end of the plate and the two sides formed by the internal flow channels are assumed to be adiabatic boundaries, as are the top and bottom faces. The cavity flood gap end of the plate is cooled by single-phase mixed convection, or boiling heat transfer if the wall superheat exceeds $15^{\circ} \mathrm{C}$. The singlephase convective heat transfer (htc) coefficient is $72.4 \mathrm{~W} / \mathrm{m}^{2}-\mathrm{K}$, which corresponds to laminar flow through a one inch gap. With the onset of boiling, the heat transfer coefficient is conservatively assumed to be 2000 $\mathrm{W} / \mathrm{m}^{2}-\mathrm{K}$, the pool boiling value associated with a wall superheat of $10^{\circ} \mathrm{C}$ [2]. The conservatism is a result of delaying the wall superheat for the onset of nucleate boiling (ONB), by $5^{\circ}$ to $15^{\circ} \mathrm{C}$, where the boiling htc would be in excess of $5000 \mathrm{~W} / \mathrm{m}^{2}-\mathrm{K}$. The cavity flood free stream temperature is the local saturation temperature based on a free surface at atmospheric pressure and with an elevation of approximately $6.4 \mathrm{~m}$ above the top of the module. The initial plate temperature is assumed to be $100^{\circ} \mathrm{C}$, and the transient calculation commences 100 seconds after beam shutdown. A dryout time of 100 seconds is an extremely conservative estimate in view of the available decay power and the inventory of water in the modules. With no flow through the row 1 modules, three hours are required to heat the liquid inventory to saturation, and an additional twenty-five hours are required to boil-off the liquid [4]. The average plate power is a function of the elapsed time from beam shutdown. The initial 100 hours after beam shutdown is simulated

Table 1. Pre-incident powers for the hot plate in the three modules.

\begin{tabular}{|c|c|c|}
\hline \multirow{3}{*}{$\begin{array}{l}\text { Front Lateral } \\
\text { Module }\end{array}$} & Geometry A & $60.67 \mathrm{~kW}$ \\
\hline & Geometry B & $82.60 \mathrm{~kW}$ \\
\hline & Geometry C & $104.50 \mathrm{~kW}$ \\
\hline \multirow{3}{*}{$\begin{array}{c}\text { Back Lateral } \\
\text { Module }\end{array}$} & Geometry A & $76.60 \mathrm{~kW}$ \\
\hline & Geometry B & $103.70 \mathrm{~kW}$ \\
\hline & Geometry C & $130.10 \mathrm{~kW}$ \\
\hline Downstream Module & Geometry A & $88.80 \mathrm{~kW}$ \\
\hline
\end{tabular}




\begin{tabular}{||l||c||c||}
\hline 1 & Geometry B & $137.30 \mathrm{~kW}$ \\
\hline & Geometry C & $189.60 \mathrm{~kW}$ \\
\hline
\end{tabular}

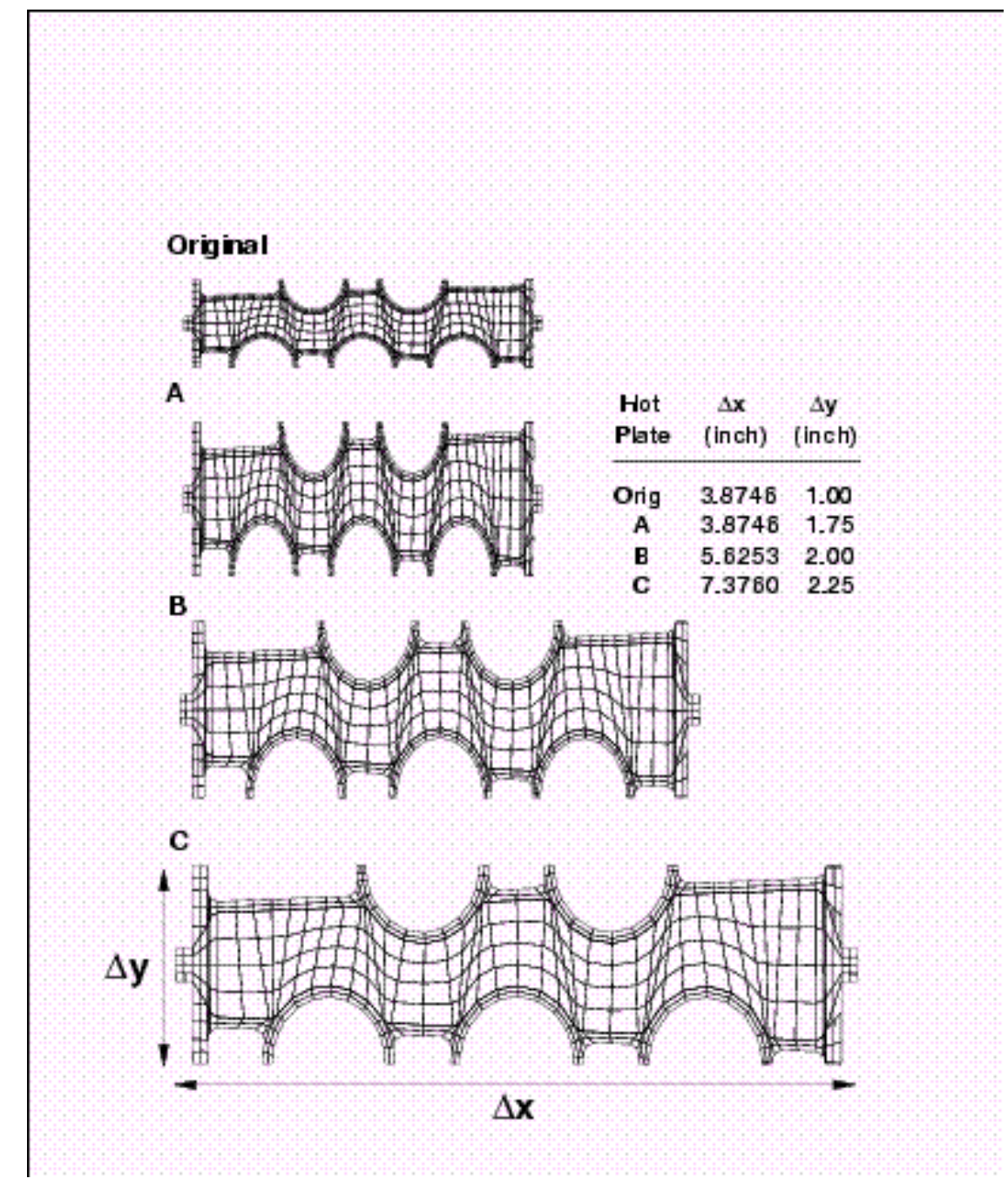

Figure 1. Horizontal cross-sections of the original and the three modeled plate designs with HEATEL finite element grids (all grids shown in scale). 


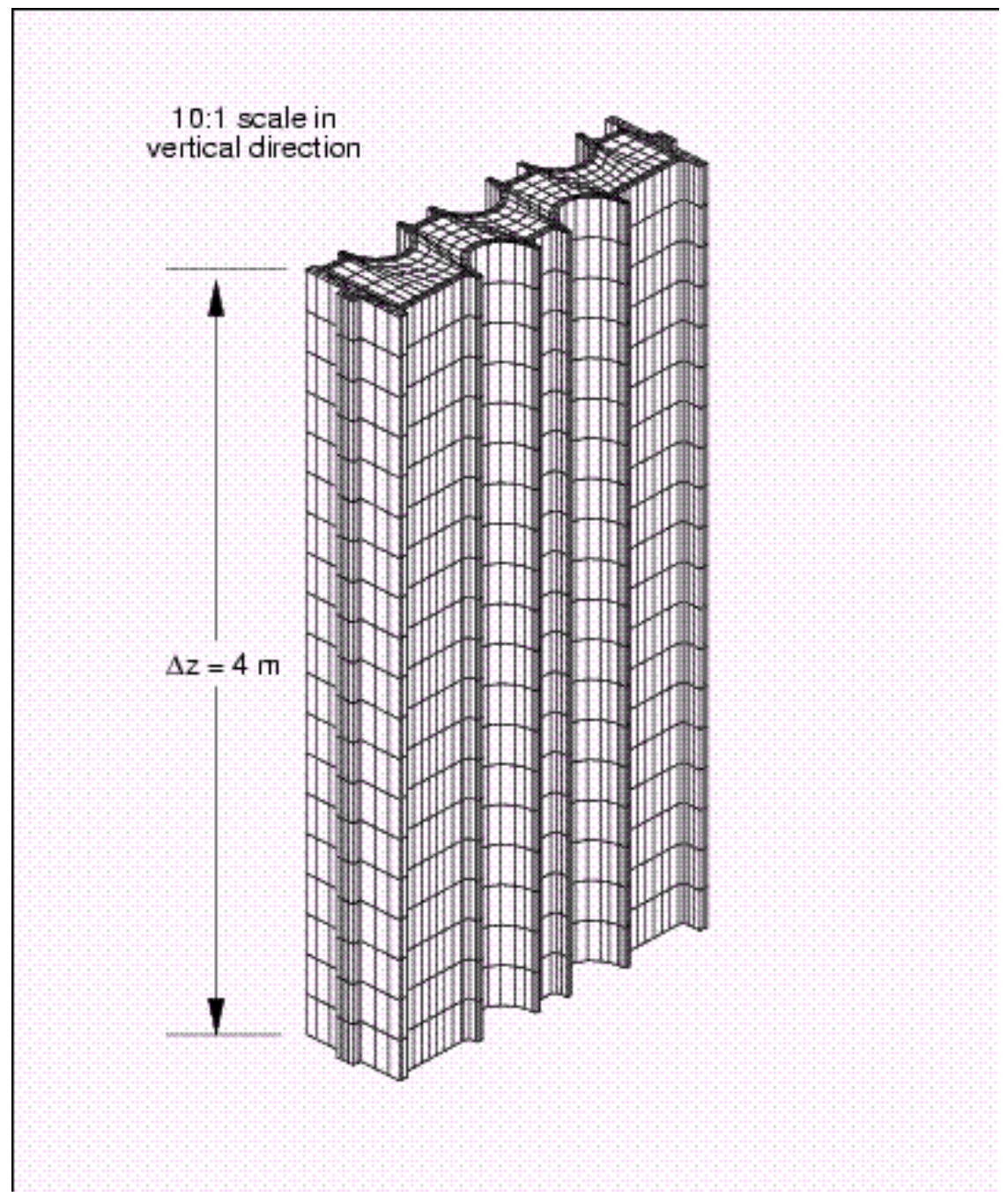

Figure 2. Three-dimensional mesh of the row 1 plate $\mathrm{C}$ design.

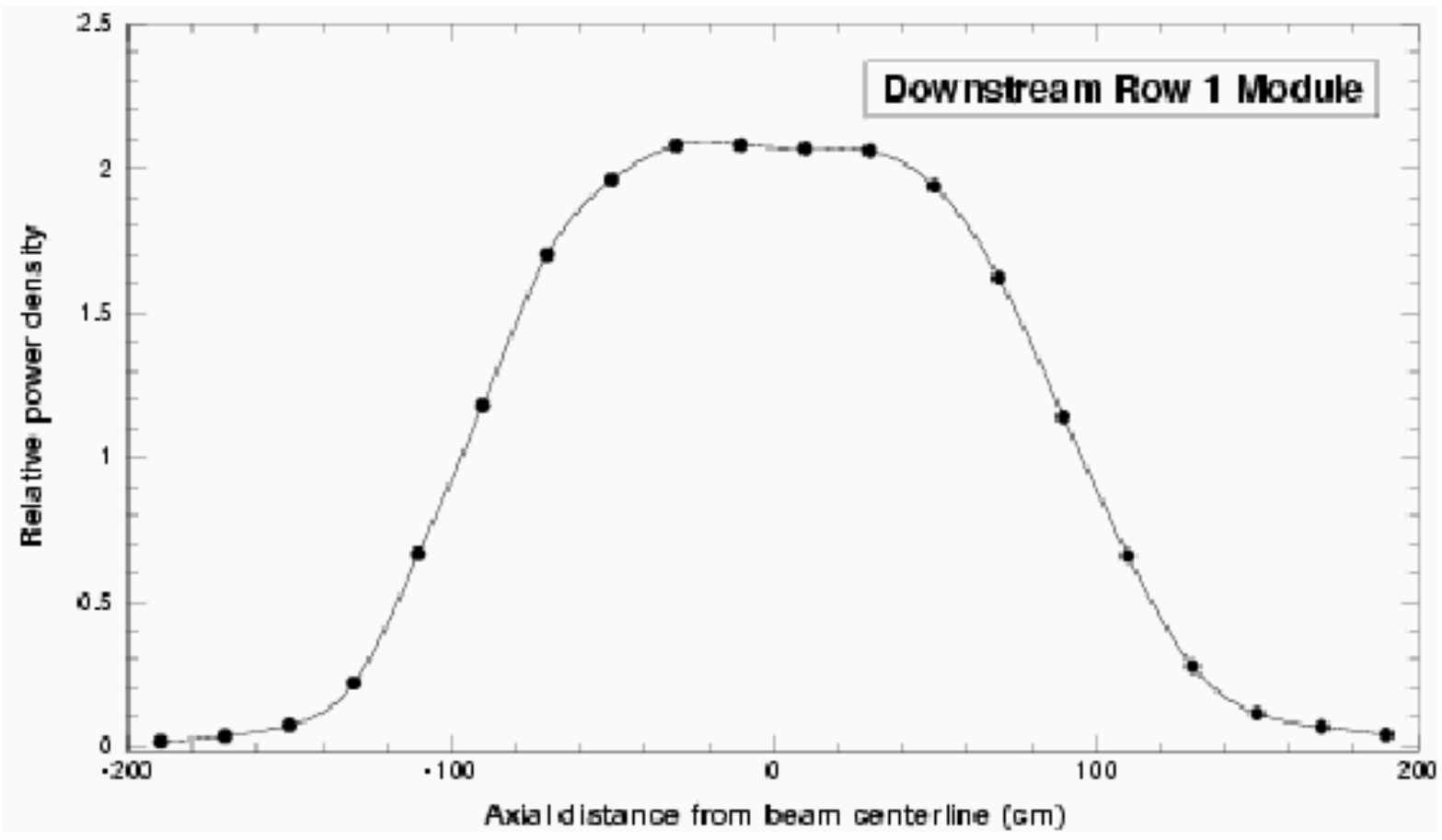


Figure 3. Axial power density profile in the downstream row 1 module.

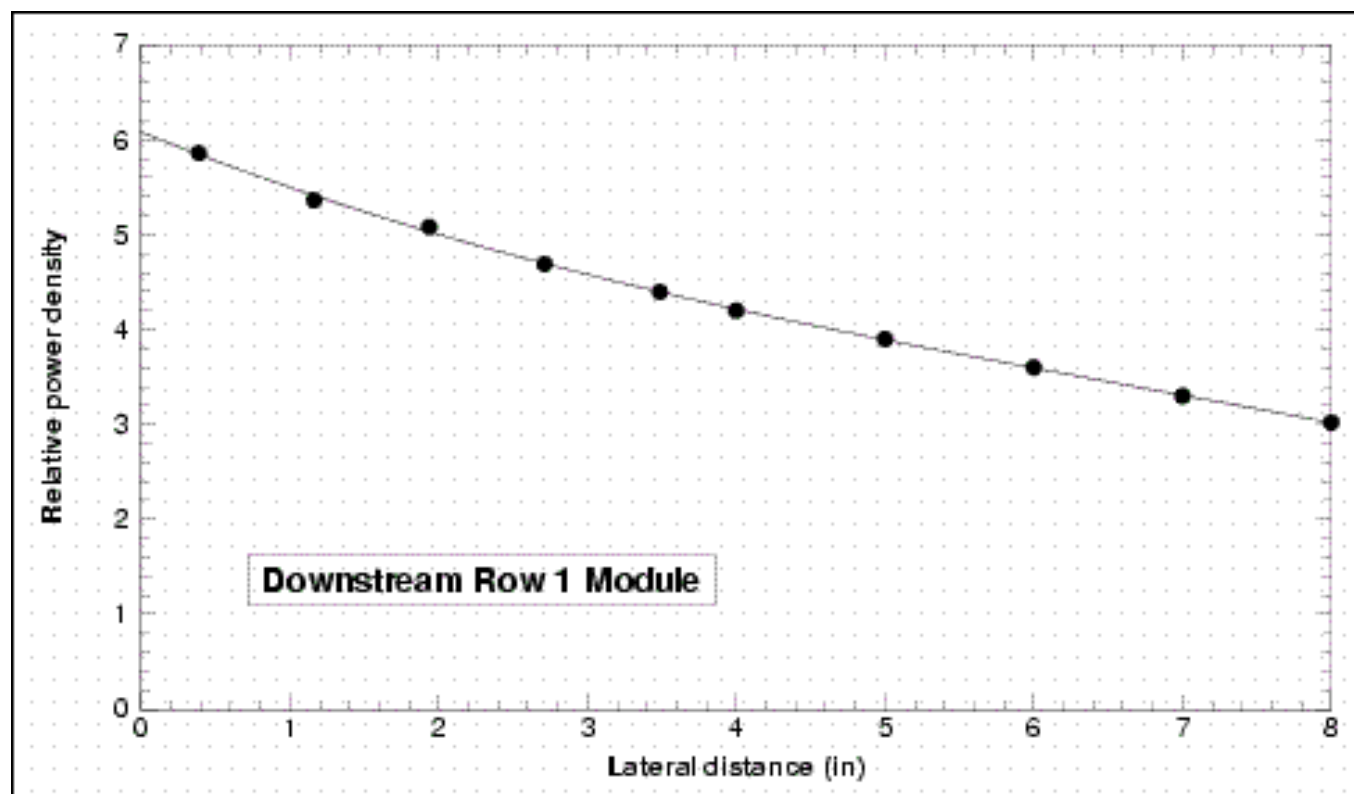

Figure 4. Horizontal lengthwise power density profile in the hot plate of the downstream row 1 module, plate $\mathrm{C}$ design.

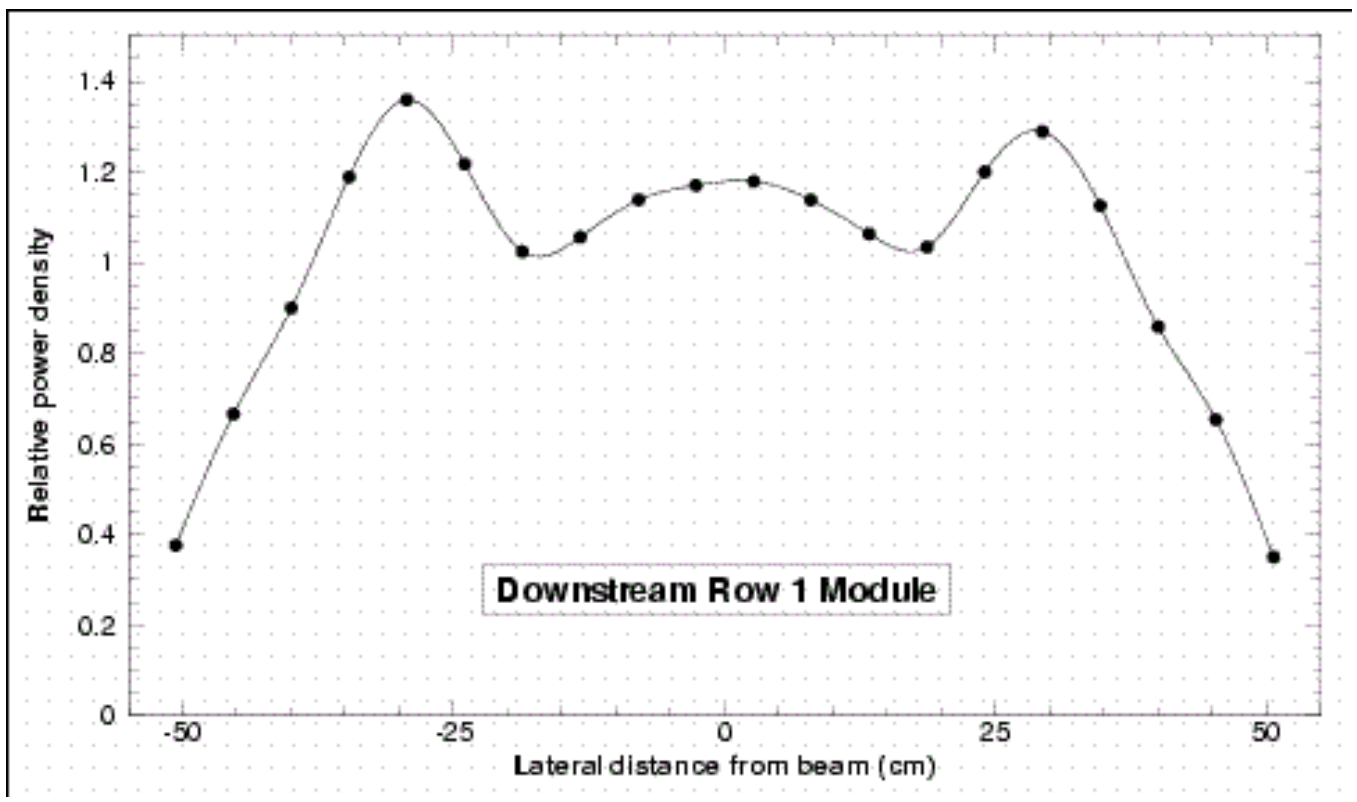

Figure 5. Horizontal power density profile, perpendicular to the beam, in the downstream row 1 module. 
Figure 6 shows the temperature distribution in a horizontal slice of hot plate $C$ at the elevation where, and at the elapsed time that, the peak temperature occurs. This elevation is near the mid-plane of the plate. For the three hot plate geometries considered, Figures 7a through 7c show the transient maximum (in space) plate temperatures and the gap wall and cavity fluid temperatures at the same elevation. The peak (in time and space) metal temperature occurs early in the transient at the decoupler end of the plate. The maximum metal temperature exceeds $150^{\circ} \mathrm{C}$ for a brief period of time with hot plate $\mathrm{C}$, the long plate design. The oscillations in the wall temperature occur due to the assumed step function nature of boiling in this model. During the early phase of the transient, the time step was shortened to minimize the effect of wall temperature oscillations on the maximum metal temperature. For hot plate $\mathrm{C}$, the surface heat flux at the axial elevation where the peak metal temperature occurs is shown in Figure 8. Figure 9 shows the transient maximum metal temperatures for the three hot plate geometries on a single plot. Figure 10 shows the peak metal temperature, both spatially and temporally, as a function of plate length. The relationship is slightly non-linear. The peak temperature for hot plate $\mathrm{C}$, the proposed long plate design, is $153.6^{\circ} \mathrm{C}$. Figure 11 shows the axial profile at the time that the peak temperature occurs for hot plate $\mathrm{C}$ where maximum metal temperatures at each horizontal plane were chosen. Also shown are axial profiles of the wall, ONB, and cavity flood fluid temperatures (i.e., maximum values at each horizontal plane). The central portion of the gap, from approximately one to three meters axially, is at the ONB threshold. The decay power is insufficient to sustain boiling with the heat transfer coefficient utilized in the model, so the wall temperature oscillates, rising when the single-phase heat transfer coefficient is applied and dropping when the boiling heat transfer coefficient is applied. This situation persists for approximately 45 hours after beam shutdown, as indicated by the oscillations in surface temperature in Fig. 7c. Thereafter, the decay power drops below the level required for a single-phase wall/free stream temperature difference of $15^{\circ} \mathrm{C}$.

Table 2 presents the results of a model sensitivity study. Five parameters in the hot plate $\mathrm{C}$ model were perturbed separately, and the resultant peak metal temperatures are presented. Also shown is the unperturbed (nominal) case. Raising the pre-incident plate power by $20 \%$ increases the peak metal temperature by $5.8^{\circ} \mathrm{C}$. Decreasing the $\mathrm{ONB}$ wall superheat to $10^{\circ} \mathrm{C}$ drops the peak temperature by $3.7^{\circ} \mathrm{C}$. Increasing the boiling heat transfer coefficient from $2000 \mathrm{~W} / \mathrm{m}^{2}-\mathrm{K}$ to $5000 \mathrm{~W} / \mathrm{m}^{2}-\mathrm{K}$ drops the peak temperature by $1.0^{\circ} \mathrm{C}$. Increasing the cavity flood free surface elevation above the top of the module from 6.4 to $8.2 \mathrm{~m}$ increases the peak temperature by $2.8^{\circ} \mathrm{C}$. Eliminating the air gap between the lead and the aluminum decreases the peak temperature by $1.3^{\circ} \mathrm{C}$. Figure 12 shows the peak temperatures for hot plate $\mathrm{C}$ as a function of the elapsed time from beam shutdown to the onset of dryout. The precise time of dryout is a function of the specific LOCA being considered. A post beam shutdown dryout delay time of 100 seconds is clearly bounding. Figure 12 shows the effect of relaxing this assumption and allowing a longer period for dryout to occur. The threshold dryout time for a peak temperature below $150^{\circ} \mathrm{C}$ is 80.0 minutes. Based on these preliminary sensitivity studies, an overall uncertainty in predicting the peak metal temperature should fall within $3-4^{\circ} \mathrm{C}$.

Figure 14 shows the peak metal temperatures for case $\mathrm{C}$ design plates in the downstream and front/back lateral row 1 modules, as a function of the pre-incident deposited power. These results are for dryout times of 100 seconds. For a given plate power, the peak temperatures for plates in the two lateral modules are considerably higher than the peak temperature in a plate in the downstream module. This is due to the differences in the spatial power distributions in the plates. The axial deposited power distributions for the three modules are very similar and therefore do not substantially contribute to this peak temperature versus deposited power difference. Figure 14 shows the horizontal lengthwise relative deposited power profiles for plates in the three modules under consideration. These profiles are normalized with respect to the average power densities in the plates. The deposited power profiles are considerable more peaked towards the adiabatic decoupler ends of the plates in the lateral modules than in the downstream module. The normalized deposited power densities at the decoupler ends of the plates in the lateral modules are approximately 3.2 whereas it is approximately 1.4 for the downstream module. The difference in preincident deposited power between the case $\mathrm{C}$ design hot plate of the downstream module, $189.6 \mathrm{~kW}$, and 
the hot plates in the lateral modules, $104.5 \mathrm{~kW}$ in the front lateral module and $130.1 \mathrm{~kW}$ in the back lateral module, more than compensates for this power distribution difference. The peak temperatures for the hot plates of the two lateral modules are $146.0^{\circ} \mathrm{C}$ and $150.2^{\circ} \mathrm{C}$ for the front and back modules, respectively; whereas, the peak temperature for the downstream module hot plate is $153.6^{\circ} \mathrm{C}$.

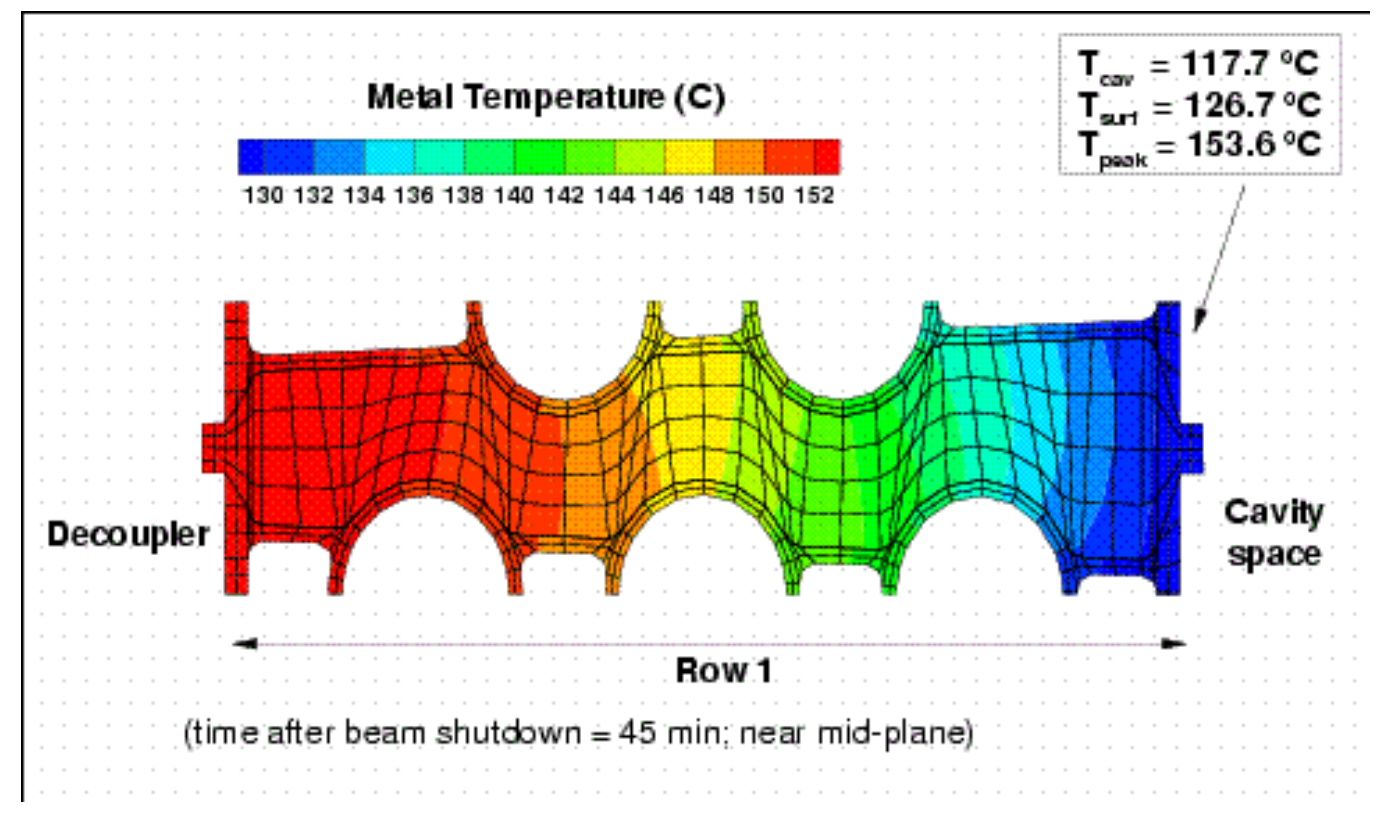

Figure 6. Temperature distribution in a horizontal slice of a plate (near the mid-plane) at the elevation where, and at the elapsed time that, the peak temperature occurs (hot plate C: 7.3760" by $2.25 "$ ).

Table 2. HEATEL sensitivity study results for hot plate $C$.

\begin{tabular}{|c|c||}
\hline Perturbed Parameter & $\begin{array}{c}\text { Peak Metal } \\
\text { Temperature }\left({ }^{\circ} \mathbf{C}\right)\end{array}$ \\
\hline \hline Nominal Case & 153.6 \\
\hline \hline $20 \%$ increase in power & 159.4 \\
\hline \hline $10^{\circ} \mathrm{C}$ ONB wall superheat & 149.9 \\
\hline Boiling htc set at $5000 \mathrm{~W} / \mathrm{m}^{2}-\mathrm{K}$ & 152.6 \\
\hline \hline Cavity flood free surface $8.2 \mathrm{~m}$ above module & 156.4 \\
\hline \hline No gap between lead and aluminum & 152.3 \\
\hline
\end{tabular}




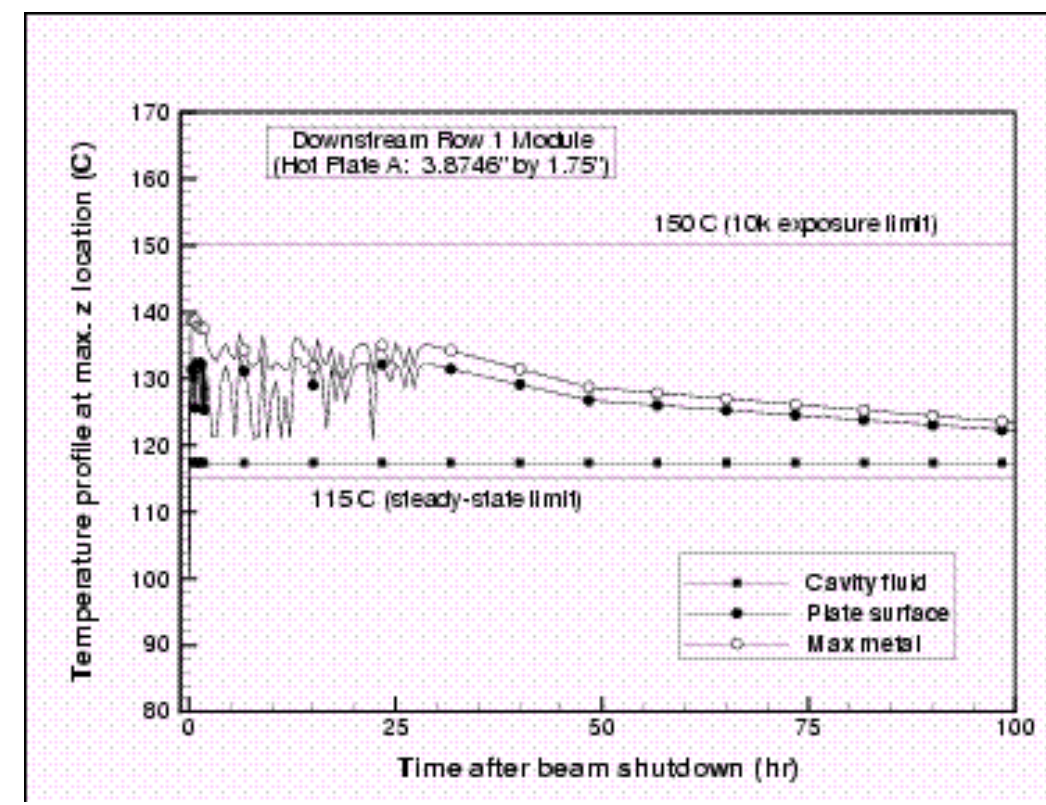

Figure 7a. Maximum metal temperatures, with wall and cavity fluid temperatures at the same elevation, for the downstream row 1 module (hot plate A: 3.8746" by 1.75").

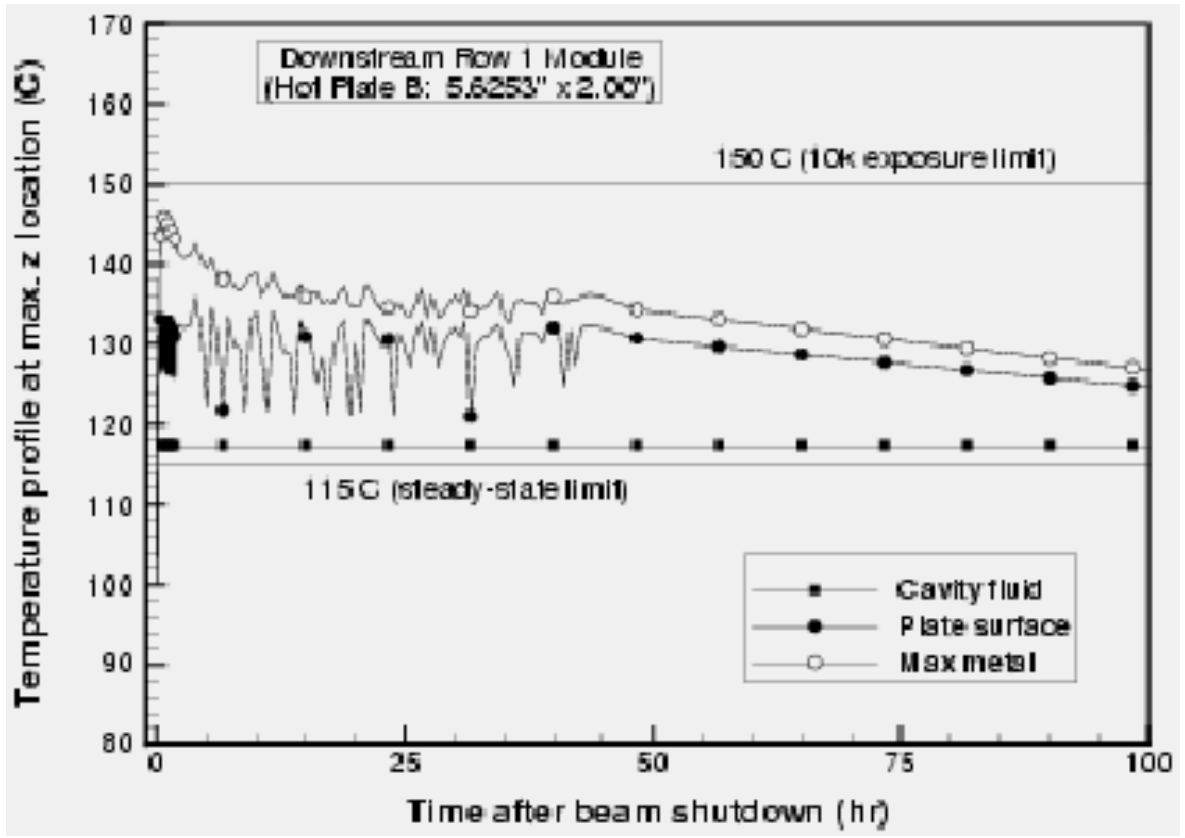

Figure 7b. Maximum metal temperatures, with wall and cavity fluid temperatures at the same elevation, for the downstream row 1 module (hot plate B: 5.6253" by $2.0 "$ ). 


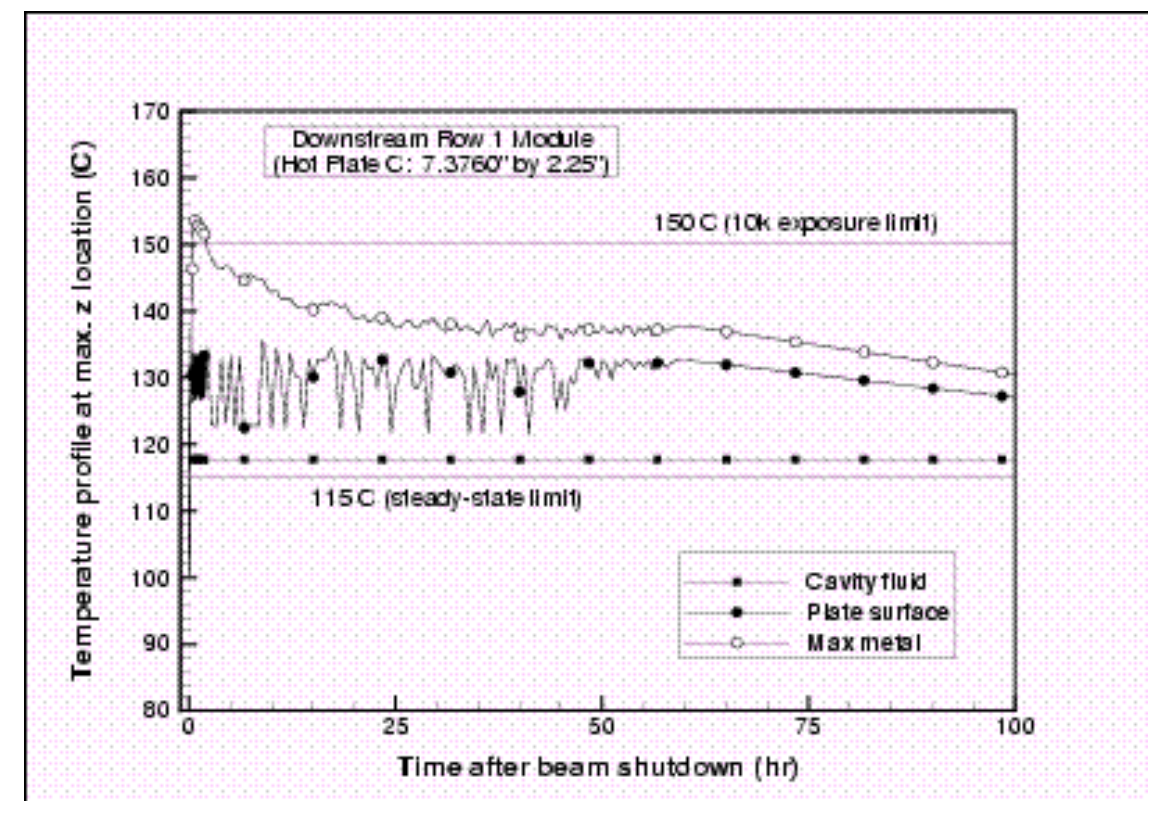

Figure 7c. Maximum metal temperatures, with wall and cavity fluid temperatures at the same elevation, for the downstream row 1 module (hot plate C: 7.3760" by $2.25 "$ ).

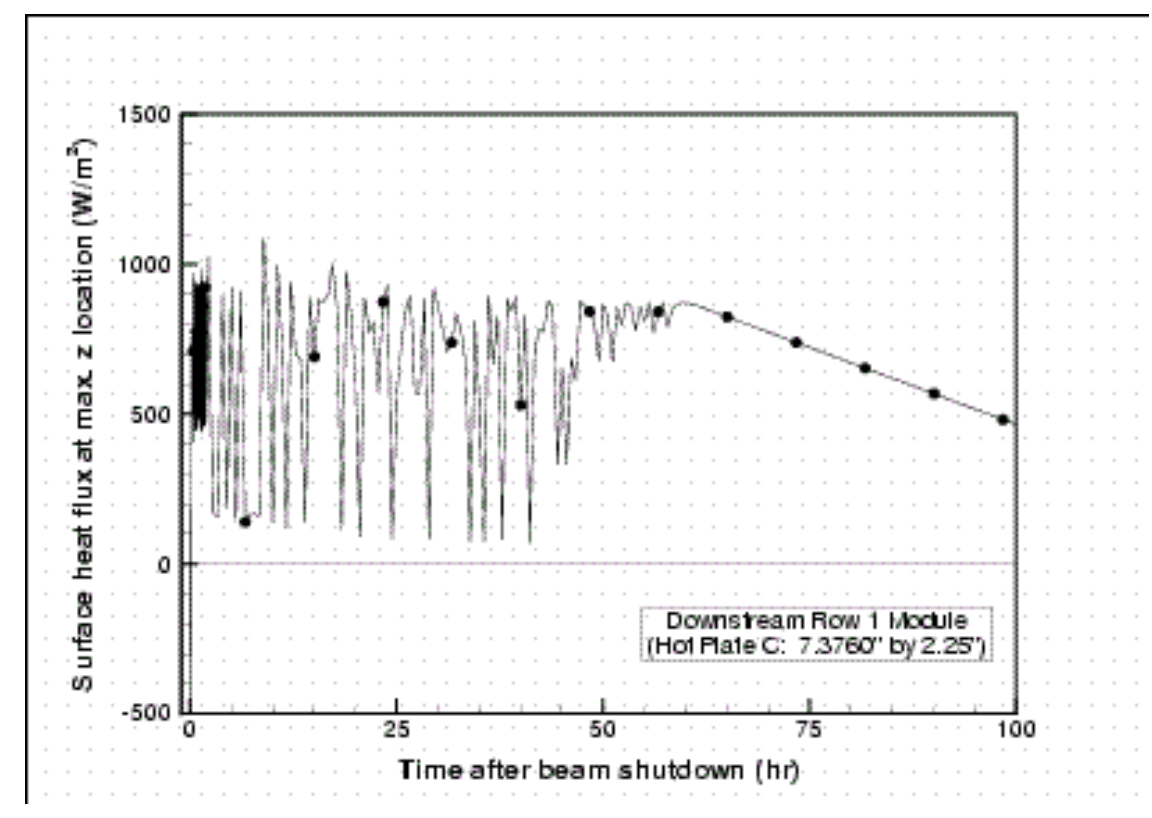

Figure 8. Surface heat flux at the axial elevation where the peak metal temperature occurs for the downstream row 1 module (hot plate C: 7.3760" by 2.25"). 


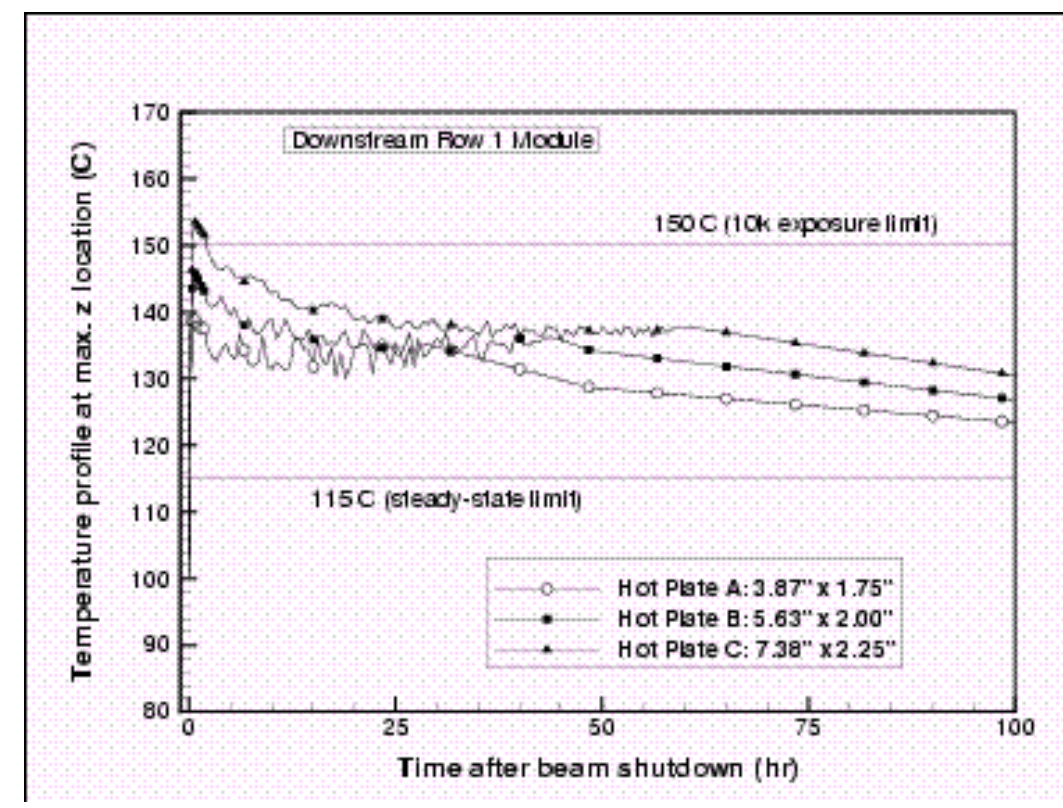

Figure 9. Maximum metal temperatures for the downstream row 1 module for the three plate geometries considered.

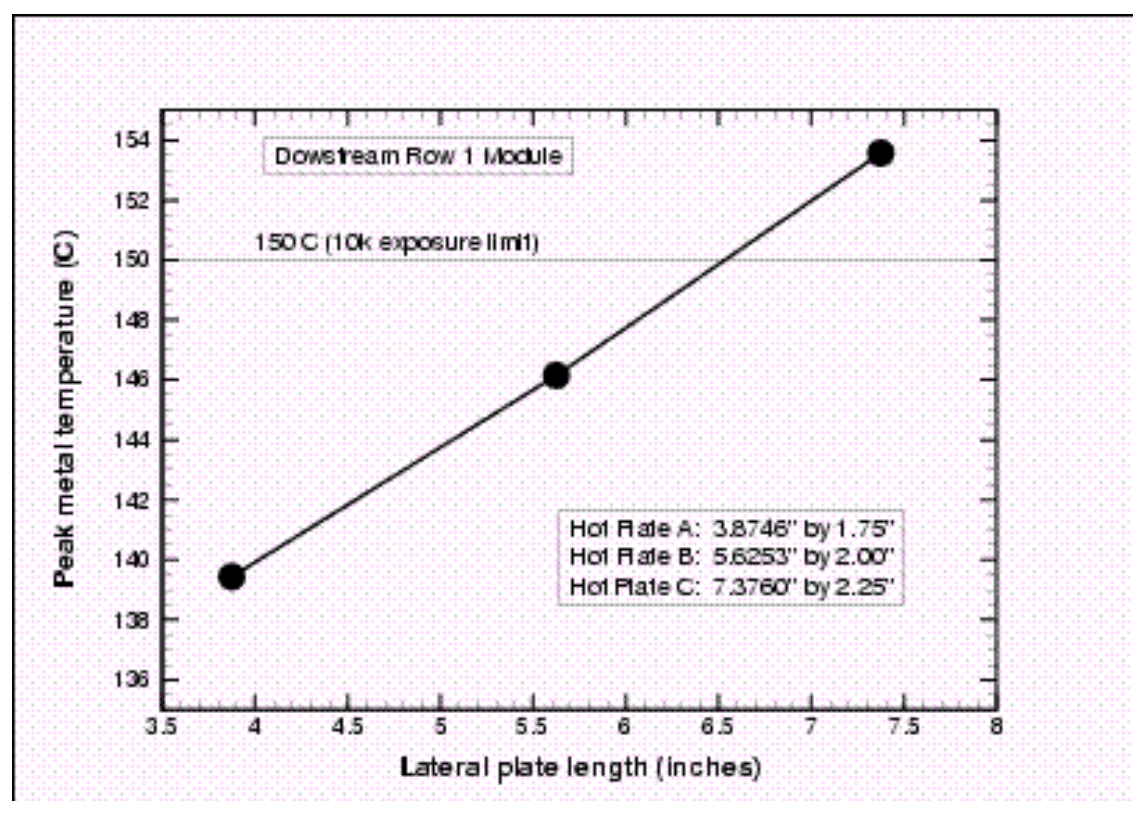

Figure 10. Peak metal temperatures for the downstream row 1 module as a function of plate length. 


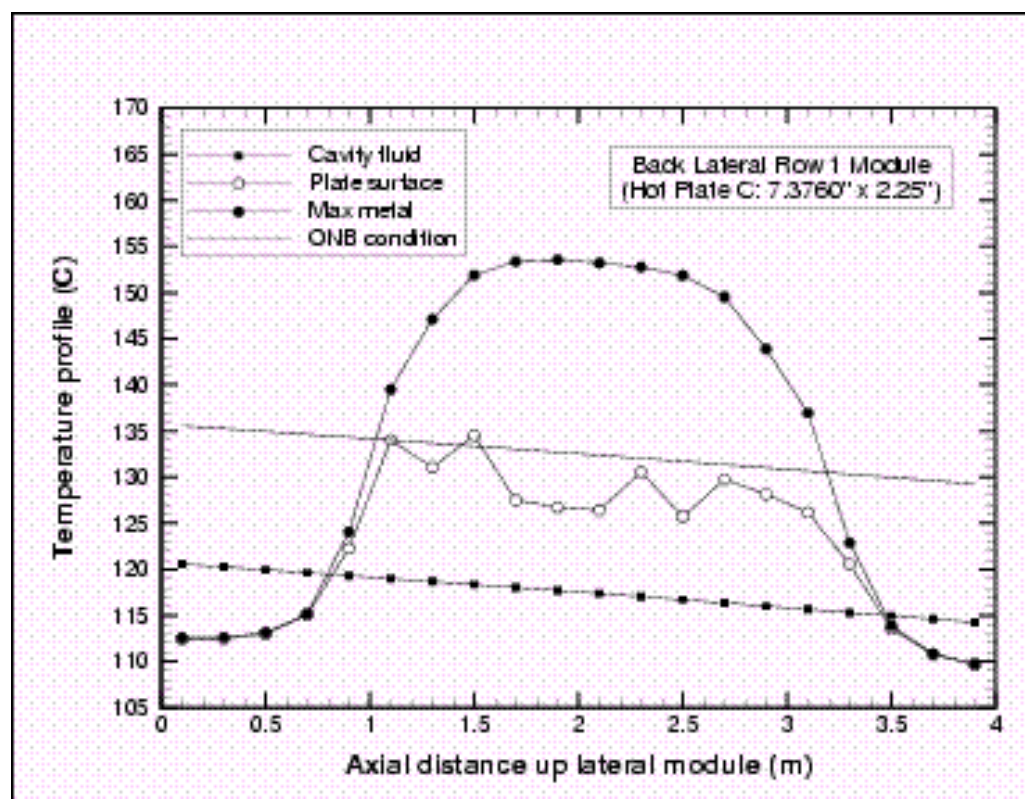

Figure 11. Axial temperature profiles at the time of the peak temperature (hot plate C: 7.3760" by $2.25 "$ ).

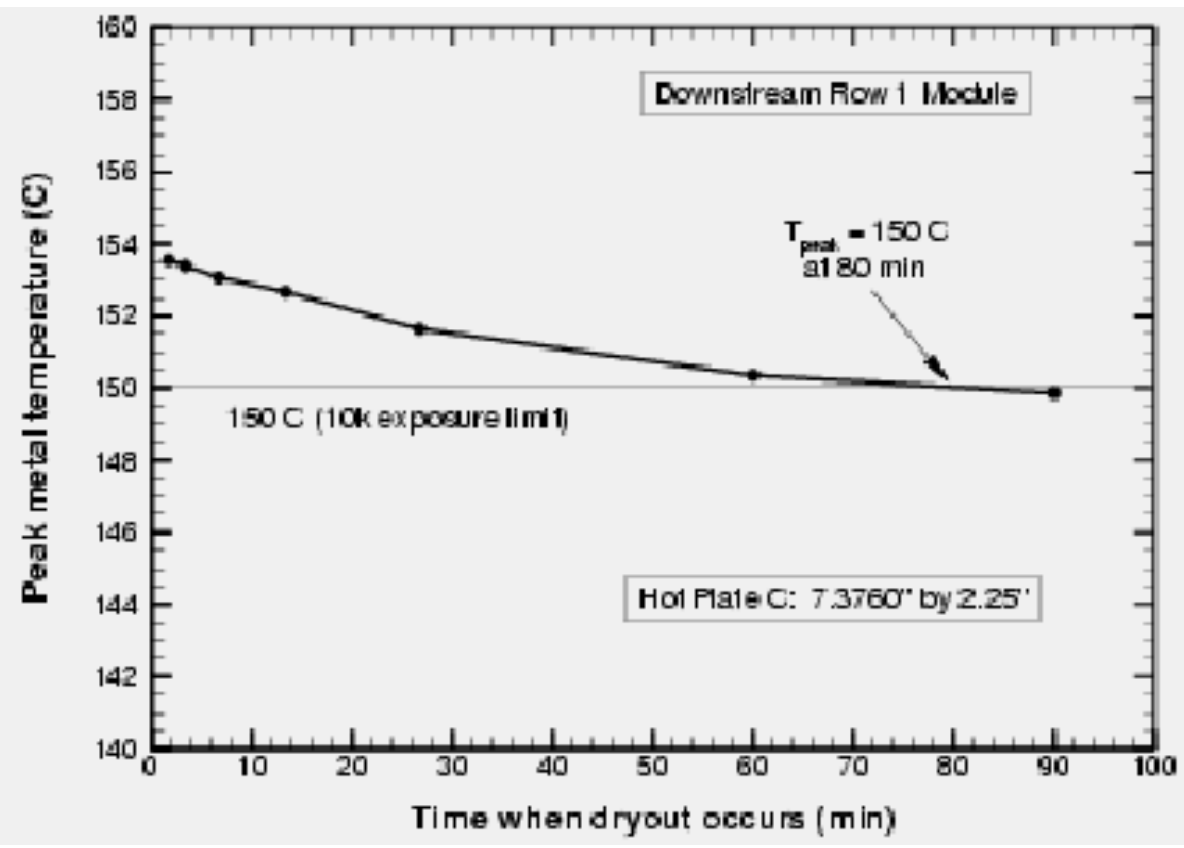

Figure 12. Peak metal temperatures as a function of elapsed time from beam shutdown to the onset of module dryout (Case C: 7.3760" by 2.25"). 


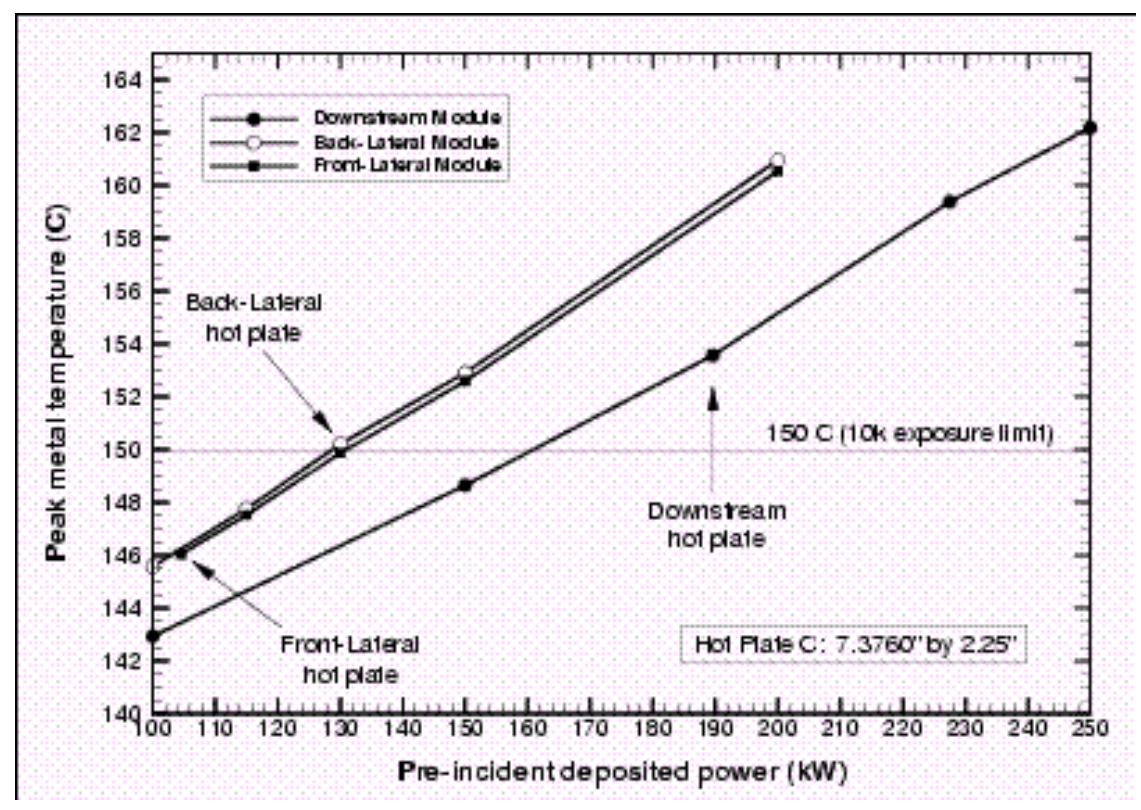

Figure 13. Peak metal temperatures as a function of pre-incident deposited power in plates in downstream and lateral row 1 modules (Case C: 7.3760" by $2.25 "$ ).

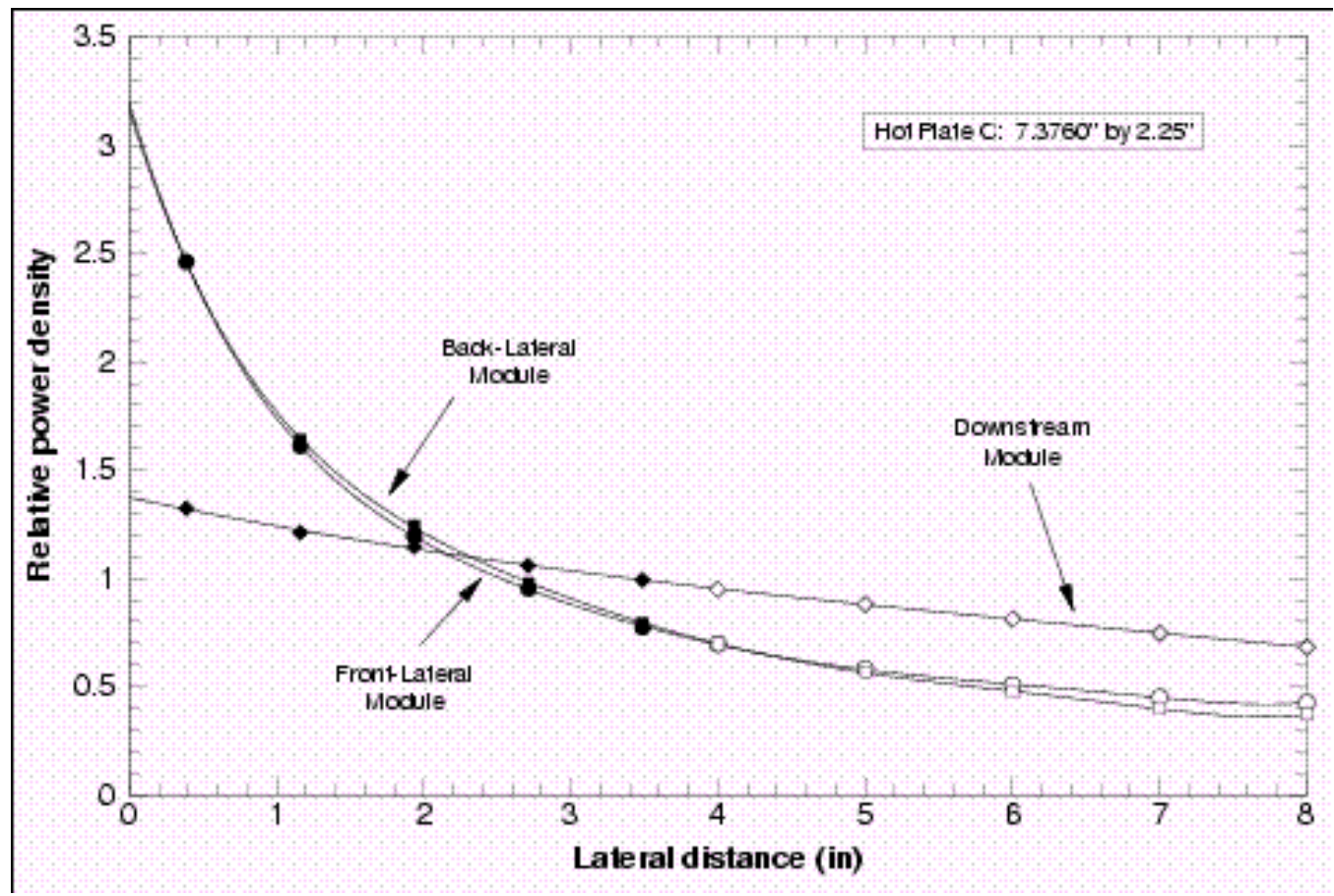

Figure 14. Horizontal lengthwise relative deposited power profiles for plates in the three row 1 modules considered (Solid symbols data, [3], open symbols extrapolated).

\section{Conclusions}

The peak temperature of hot plate $\mathrm{C}$, the $7.5^{\prime \prime}$ plate design, is $153.6^{\circ} \mathrm{C}$ with an overall uncertainty of less than $3-4^{\circ} \mathrm{C}$. This exceeds the $150^{\circ} \mathrm{C}$ long-term exposure metal temperature limit for blanket components, 
but only for a brief period (i.e., less than five hours of exposure). The highest power plate in all of the row 1 modules was conservatively modeled. The peak temperatures of most of the lateral and downstream row 1 plates will be below the temperature limit. The beamwise power distribution multiplier for the back plate in a front lateral row 1 module is 1.59. This is the ratio of the average power for the back plate to the module average plate power. The beamwise power distribution multiplier for the front plate in a back lateral row 1 module is 1.38 , and the transverse power distribution multiplier for the hot plate in the downstream module is 1.36 .

The assumption that a row 1 module is drained at 100 seconds after beam shutdown is not realistic, and this is probably the most significant conservative assumption in these analyses. If the elapsed time from beam shutdown to the onset of dryout exceeds 80 minutes, the peak temperature in hot plate $\mathrm{C}$ will be below the $150^{\circ} \mathrm{C}$ temperature limit.

Therefore, it is concluded that the cavity flood system can adequately cool lateral and downstream row 1 modules with 7.5" plates, even when the modules are internally dry. This conclusion is supported by: (1) the bounding nature of these analyses and (2) the brief period of exposure time and limited spatial extent of the region predicted to exceed this temperature limit.

\section{References}

1. L. L. Hamm, S. Y. Lee, M. A. Shadday, and F. G. Smith, III, "APT PSAR Blanket Safety Analysis Based on Initial Conceptual Design," Westinghouse Savannah River Company, WSRC-TR-98-0087 (July 1998).

2. L. L. Hamm, S. Y. Lee, M. A. Shadday, and F. G. Smith, III, "APT Blanket System Internally Dry Flooded Cavity Accident (IDFCA) Based on Initial Plate-Type Design - Demonstration of Bin Heat Conduction Capability," Westinghouse Savannah River Company, WSRC-TR-98-0064 (July 1998).

3. R. Kapernick, EXCELL Spread Sheet: Lat R1, 1.5kg, received from Los Alamos National Laboratory, March 1999.

4. L. L. Hamm, S. Y. Lee, M. A. Shadday, and F. G. Smith, III, "Blanket Module Boil-Off During a Loss-Of-Coolant Accident (LOCA) - Case 0: with Beam Shutdown only," Westinghouse Savannah River Company, WSRC-TR-98-00213 (July 1998). 